
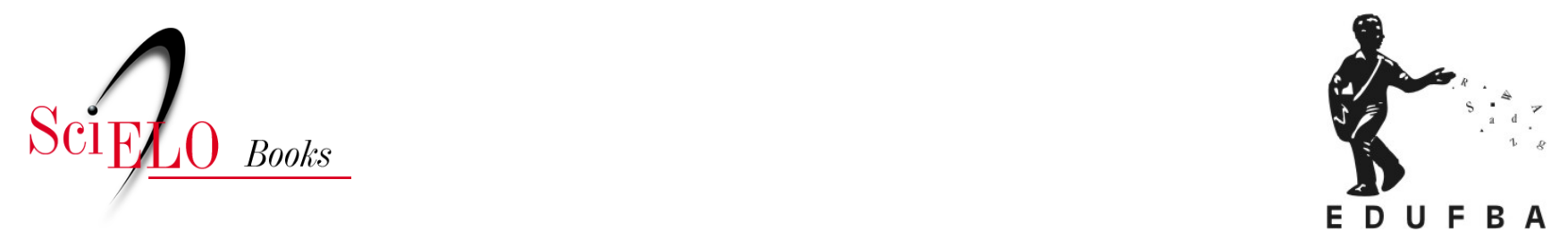

\title{
Luta pública contra o TID ações de advocacy e campanhas de sensibilização
}

\author{
Danila Gentil Rodriguez Cal
}

\section{SciELO Books / SciELO Livros / SciELO Libros}

CAL, D.G.R. Luta pública contra o TID: ações de advocacy e campanhas de sensibilização. In: Comunicação e trabalho infantil doméstico: política, poder, resistências [online]. Salvador: EDUFBA, 2016, pp. 49-73. ISBN: 978-85-232-1870-6. https://doi.org/10.7476/9788523218706.0005.

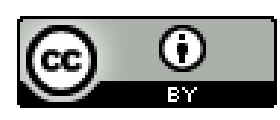

All the contents of this work, except where otherwise noted, is licensed under a Creative Commons Attribution $\underline{4.0 \text { International license. }}$

Todo o conteúdo deste trabalho, exceto quando houver ressalva, é publicado sob a licença $\underline{\text { Creative Commons }}$ Atribição 4.0. 


\section{Luta pública contra o TID: ações de advocacy e campanhas de sensibilização}

- [...] eu nessa época eu tinha medo, eu não falava, tanto que eu apanhava, me escondia, mas não falava nada, porque eu tinha medo de perder o emprego. Para onde é que eu ia se eu saísse dali? Eu não ia conseguir outro... Mas, hoje em dia, não. Se eu discutir com a minha patroa hoje, eu perco, amanhã eu me viro e arranjo outro. Mas na adolescência é diferente. Realmente, a adolescente tem medo, principalmente aquelas que são maltratadas em casa pelos pais. Eu vou sair daqui vou para onde?

Tamires, participante do Grupo focal “Condomínio”. 
A discussão sobre o TID só entrou na agenda social no Brasil a partir de $1999^{1}$ e, principalmente, na primeira metade da década de 2000. O debate se beneficiou de uma já articulada rede de organizações internacionais e nacionais de combate ao trabalho infantil. Nessa época, apesar de a necessidade e a importância da erradicação do trabalho infantil já estarem, de modo geral, tematizadas publicamente, não havia um debate nacional sobre as atividades exercidas por crianças e adolescentes em casas de família.

A própria construção da expressão "trabalho infantil doméstico", que começa a ganhar visibilidade nesse período, é resultado da politização do tema por meio da atuação de organizações sociais pelo seu enfrentamento. (CAL, 2007; FUNDO DAS NAÇÕES UNIDAS PARA A INFÂNCIA, 1999) Isso porque, como vimos anteriormente, essa atividade não era reconhecida como "trabalho", dificuldade que permanece ainda hoje. $\mathrm{E}$ as formas de nomeá-la variavam entre outras expressões, como "dar uma ajuda”, "reparar menino”, entre outras. Além disso, as crianças e adolescentes que exerciam essa função eram chamadas de "crias da casa”, "meninas da casa”, “afilhadas”, e não de trabalhadoras domésticas.

Desse modo, o enfrentamento ao TID no Brasil ocorreu principalmente por meio de projetos e ações de advocacy, desenvolvidos por atores locais e nacionais de forma conjunta com organismos internacionais, entre os quais a OIT, o Unicef e a organização inglesa Save The Children. Políticas de advocacy são estratégias comumente utilizadas por organizações sociais e organismos internacionais como ações de defesa ou de promoção de determinada causa ou demanda. (LIBARDONI, 2000) Assim, no caso do TID, esse processo foi iniciado por entidades e grupos que advogavam pelos direitos de crianças e adolescentes envolvidos no TID num contexto social em que essa prática era largamente aceita. (CENTRO DE DEFESA DA CRIANÇA E DO ADOLESCENTE, 2002)

De acordo com Libardoni (2000, p. 208), advocacy diz respeito a:

[...] iniciativas de incidência ou pressão política, de promoção e defesa de uma causa e/ou interesse, e de articulações mobilizadas por organizações da sociedade civil com o objetivo de dar maior visibili-

\footnotetext{
1 O relatório da OIT (2003) sobre boas práticas no enfrentamento do trabalho infantil cita uma experiência pontual que ocorreu entre 1993 e 1995 no município de Campos dos Goitacazes (RJ) para o enfrentamento de 50 casos de TID, executada pelo IPEC/OIT em parceria com o governo municipal, mas que não gerou repercussão mais ampla.
} 
dade a determinadas temáticas ou questões no debate público e in-

fluenciar políticas visando à transformação da sociedade.

Mafra (2014) constrói de modo detalhado a trajetória desse conceito e ressalta que advocacy tanto "carrega uma possibilidade de sentido voltada a designar ações de sujeitos que assumem uma causa não ligada diretamente a suas próprias experiências do vivido" (MAFRA, 2014, p. 198) quanto pode designar ações empreendidas por sujeitos afetados pela causa advogada, mas que têm como intuito representar outros tantos que passaram pelas mesmas situações ou vivenciam os mesmos tipos de problema. O modo preponderante pelo qual o enfrentamento ao TID foi articulado condiz com a primeira acepção do termo.

Apesar da contribuição dos grupos de advocacy para colocar em discussão temas e políticas que objetivam garantir ou promover direitos de determinados grupos que detém, por vezes, pouco poder de influência, há uma tensão entre o que se diz em nome desses grupos e o que seriam seus interesses efetivos. Para Miguel (2011), de modo subjacente aos modelos de advocacy, normalmente é possível encontrar expressões de paternalismo e de autoritarismo. Isso ocorre em grande medida porque as vozes e os discursos que ganham ressonância na esfera pública são de agentes de advocacy, e não dos sujeitos realmente concernidos. Nesse sentido, de acordo com Miguel (2011), é fundamental que esses grupos ou agentes de advocacy se mantenham em diálogo com os sujeitos que desejam representar.

Segundo Miguel (2011, p. 54),

[...] os advocates promovem uma forma de substituição que faz com que a autoexpressão dos dominados deixe de aparecer como um problema a ser enfrentado. Afinal, seus direitos ou interesses já se fazem ouvir, defendidos por grupos e indivíduos melhor capacitados.

A nosso ver, esse dilema tende a repercutir na forma como a luta contra o TID é tornada pública pelas organizações sociais (nas campanhas de publicidade) e pelos media. Tomamos como uma das nossas hipóteses de trabalho que o espaço destinado à fala e ao posicionamento de meninas e mulheres afetadas pelo TID nos media destina-se, principalmente, à expressão do sofrimento e das mazelas relacionadas ao trabalho infantil. Assim, as discussões mais políticas, 
sobretudo acerca de direitos e interesses, seriam atribuídas a especialistas e representantes de organizações sociais.

Casos de advocacy acerca da infância e da adolescência trazem desafios particulares à "autoexpressão dos dominados". Especialistas e advocates geralmente são considerados atores mais apropriados e com mais possibilidade de repercussão para falar em nome de crianças e adolescentes do que eles próprios. (MIGUEL, 2011; EARLS, 2011) Como afirma Earls (2011), a cidadania de crianças e adolescentes é garantida pelo fato de nascerem em um estado, em um país. No entanto, somente são considerados cidadãos de fato, com direito à voz, quando adquirem o direito de votar, de modo que as decisões sobre o bem-estar de meninos e meninas são sempre atribuídas a figuras de autoridade, capazes de definir os seus "melhores interesses".

Earls (2011), contudo, questiona posicionamentos dessa natureza e defende que a maturidade política tem relação com a capacidade de agir em conjunto em prol do bem comum. Para ele, "mesmo se às crianças for negado acesso aos processos eleitorais, elas têm opiniões, preferências e capacidades para deliberação e ação social”. (EARLS, 2011, p. 11, tradução nossa) James (2011) corrobora essa perspectiva acrescentando que a cidadania de crianças e adolescentes é aperfeiçoada na medida em que eles deixam de ser considerados incompetentes ou irresponsáveis e passam a ser vistos como sujeitos capazes e com responsabilidades.

Apesar do enfrentamento do TID ter sido iniciado por meio de ações de advocacy de organizações internacionais, consta na maior parte dos guias e manuais que norteavam essas ações a necessidade de criar espaços de investigação sobre as condições de vida de meninos e, sobretudo, de meninas trabalhadoras domésticas. Além disso, era clara a indicação para que esse tipo de processo envolvesse o protagonismo de adolescentes. Outra recomendação era para que os programas de enfrentamento ao TID fossem liderados por organizações locais e nacionais, de preferência em parceria com grupos de mulheres, organizações não governamentais e entidades ligadas à defesa dos direitos humanos. (BLACK, 2002) Com isso, esperava-se que a iniciativa se beneficiasse de redes já organizadas nos países e envolvidas com a garantia dos direitos de mulheres e crianças, pois o TID tensiona, como dissemos anteriormente, aspectos fundamentais de gênero.

Nesse contexto, com objetivo de instrumentalizar programas de atuação e pesquisas em diferentes partes do mundo acerca dessa temática, a Anistia 
Internacional, em parceria com a OIT, publicou em 1997 o guia Child Domestic Workers: A handbook for research and action. O documento traz os resultados de um evento prévio, realizado em 1996, que reuniu representantes de nove países (sobretudo da África, Ásia e América Central) e das organizações internacionais acima citadas para pensar estratégias de investigação e de ação em relação ao TID. Além disso, o handbook objetivava dar insumos concretos ("Como começar?” e “Como encontrar o que precisamos saber?” são alguns dos temas desenvolvidos) para que a situação de trabalhadoras infantis domésticas fosse investigada em diferentes países. Essa publicação é representativa das ações internacionais nesse período, que tiveram como principal meta identificar os modos como o TID era praticado em diferentes países e qual era a situação das crianças e adolescentes envolvidas.

No Brasil, o assunto entrou em pauta a partir de seminários internacionais e nacionais realizados por organizações sociais e também, depois da produção de pesquisas sobre o TID (aspectos legais, sociais e culturais, estatísticas etc.) de abrangência nacional e local, financiadas principalmente por esses organismos internacionais e realizadas por pesquisadores brasileiros. Como mencionamos anteriormente, esse foi um importante aspecto da advocacia internacional contra o TID: envolver atores locais nas pesquisas e nas ações de enfrentamento. Outras diretrizes, como construir discursos de enfrentamento com base em contextos locais, estão bem claras nos documentos internacionais:

\footnotetext{
O trabalho infantil doméstico é uma questão que toca na vida das pessoas privadas e familiares, realidades econômicas locais, costumes e valores socioculturais. Para assinalar os danos que pode fazer às crianças, requer segurar um espelho voltado à sociedade e solicitar às pessoas que inspecionem suas atitudes para muitas coisas, incluindo a hierarquia social e infância. A advocacia é mais eficaz quando os atores locais têm o papel principal. Os papéis principais de campanhas de advocacia devem ser o de quebrar a invisibilidade atitudinal dessa prática e reduzir os casos de abuso e exploração. (FUNDO DAS NAÇÕES UNIDAS PARA A INFÂNCIA, 1999, p. 11, tradução nossa)
}

Em geral, as ações desses organismos internacionais se basearam na realização e promoção de campanhas com objetivo de estimular mudanças cultu- 
rais e de atitudes em relação ao TID; na realização de programas e projetos de intervenção para retirada de meninas desse tipo de atividade e para prevenir a inserção de crianças e adolescentes no TID; em incentivos e orientações para elaboração de políticas específicas de enfrentamento; na geração de informações e dados estatísticos sobre essa modalidade de trabalho infantil para subsidiar intervenções e disseminar conhecimentos sobre as consequências do TID e também no fortalecimento das organizações locais e nacionais envolvidas no enfrentamento dessa problemática como modo de garantir retaguarda institucional para as demandas relacionadas à erradicação do TID. (INTERNATIONAL LABOUR ORGANIZATION, 2011)

A ação dessas organizações se baseava em normativas internacionais acerca dos direitos da criança e do adolescente e sobre o trabalho infantil. Ao mesmo tempo, a atuação de organizações internacionais e nacionais também estimulou mudanças de legislação, como no caso das alterações em relação às determinações do Estatuto da Criança e do Adolescente (ECA) acerca do trabalho infantil e a definição do TID como uma das piores formas de trabalho infantil.

Na próxima seção, veremos o contexto normativo internacional e nacional acerca do TIDe, então, detalharemos o modo pelo qual o enfrentamento desse problema foi desenvolvido no país e, principalmente, no Pará, âmbito do nosso estudo de caso.

\section{NORMAS E POLÍTICAS NACIONAIS RELACIONADAS AO TID}

\section{Primeiro Princípio:}

Todas as crianças são iguais perante a vida.

As crianças terão

a garantia total de seus direitos

sem exceção de raça, credo, cor e sexo

ou classe social.

Pois, a criança, além de ser menor

é o homem em estado de poesia.

[...]

\section{Parágrafo Único:}

Todas as crianças

nos hão de reensinar a vida, 
a qual nelas floresce, em seu mistério.

Uma criança é uma criança

e todas as crianças,

por isso quando alguma nos sorri,

seja em qualquer berço

seja em qualquer mesa,

é como todas as crianças do mundo a nos dizer:

"Eu te amo! Eu te amo!

E tu... me amas?"

João de Jesus Paes Loureiro,

Poema dos Direitos da Criança, Belém, 1985.

Há convenções internacionais e normas nacionais que proíbem o trabalho infantil. Um marco fundamental é a Convenção dos Direitos da Criança, adotada pela Assembleia Geral das Nações Unidas, em 1989, e ratificada por 192 países, incluindo o Brasil. No seu artigo 32, regulamenta que os Estados

[...] reconheçam o direito da criança de estar protegida contra a exploração econômica e contra o desempenho de qualquer trabalho que possa ser perigoso ou interferir em sua educação, ou que seja nocivo para sua saúde ou para seu desenvolvimento físico, mental, espiritual, moral ou social. (BRASIL, 1990, artigo 32)

A Convenção dos Direitos da Criança também recomenda que os países criem medidas legislativas, sociais e educacionais para estabelecer uma idade mínima para admissão ao emprego, uma regulamentação apropriada sobre os horários e as condições de emprego, as quais construam penalidades e sanções aos infratores para, assim, assegurar o cumprimento desses aspectos.

No Brasil, desde 1990, está em vigor o ECA. O Estatuto considera meninos e meninas sujeitos de direitos e deveres, divide a responsabilidade entre a família, o governo e a sociedade pela proteção a crianças e adolescentes e estabelece o princípio da prioridade absoluta para a infância e adolescência nas políticas públicas. Sobre o trabalho infantil, o ECA regulamentava, até 1998, que era permitido o trabalho de adolescente a partir dos 15 anos e de menores de 14 anos como aprendizes. Por meio da Emenda Constitucional n² 20/1998, foi dada uma nova 
redação ao artigo, ficando proibido o trabalho de meninos e meninas com menos de 16 anos, salvo a partir dos 14 na condição de aprendizes. ${ }^{2}$

Existem, ainda, duas Convenções e uma Recomendação da OIT, que regulam o trabalho infantil e das quais o Brasil é signatário. A primeira é a Convenção 138, sobre a idade mínima para admissão ao emprego, que entrou em vigor em 1976 e estabelece no seu artigo terceiro que a idade mínima "não será inferior à idade de conclusão da escolaridade compulsória ou, em qualquer hipótese, não inferior a quinze anos”. (INTERNATIONAL LABOUR ORGANIZATION, 1976, artigo 3) A segunda Convenção é a 182, de 1999, e a terceira é a Recomendação 190, do mesmo ano, ambas sobre a proibição e ação imediata para eliminação das piores formas de trabalho infantil. ${ }^{3}$ De acordo com Aragão-Lagergren (2003), os preceitos destas últimas vão ao encontro das perspectivas adotadas nas normativas anteriores, cuja abordagem legal tinha como objetivo acabar com todo tipo de trabalho infantil. A Convenção 182, para Aragão-Lagergren (2003), é baseada na constatação de uma difícil realidade, a "verdade cruel de que hoje é impossível erradicar todos os tipos de trabalho infantil e, a luz disso, a melhor estratégia é concentrar [o enfrentamento] nas piores e mais intoleráveis formas de trabalho infantil”. (ARAGÃO-LAGERGREN, 2003, p. 99)

Atendendo ao disposto na Convenção 182, o governo brasileiro estabeleceu uma Comissão Nacional Tripartite, formada por representantes do governo, dos trabalhadores e dos empregadores, que resultou na Portaria $n^{\circ} 20$, de 13 de setembro de 2001, do Ministério do Trabalho. A comissão listou as 81 piores formas de trabalho infantil, nas quais o uso da mão de obra de menores de 18 anos é expressamente proibido. Nessa lista, não estava incluído o trabalho doméstico. Sete anos depois, após mobilização social estimulada por organizações como a OIT, o Unicef e a Andi - Comunicação e Direitos, o governo brasileiro incluiu o

2 O Estatuto caracteriza como "aprendizagem" "a formação técnico-profissional ministrada segundo as diretrizes e bases da legislação de educação em vigor". (BRASIL, 1990) De acordo com o artigo 63 do ECA, essa formação técnico-profissional deve obedecer aos critérios de garantia de acesso e frequência escolar ao ensino regular, atividade compatível com o desenvolvimento do adolescente e horário especial para o desenvolvimento das atividades. Ao adolescente aprendiz, devem ser assegurados os direitos trabalhistas e previdenciários. De acordo com o jurista Oris de Oliveira, não podemos considerar o TID como aprendizagem, isso porque é preciso haver alternância entre ensino teórico em centro de formação e prática, que deve ser monitorada. Segundo Oliveira, "as normas brasileiras disciplinam a aprendizagem na empresa e não se aplicam ao empregado doméstico". (OLIVEIRA, 2002, p. 12)

3 O termo "infantil", para a OIT e outras organizações internacionais, refere-se a pessoas com até 18 anos incompletos. 
TID dentre as piores formas de trabalho infantil, conforme o Decreto $n^{0} 6.481$, assinado em junho de 2008.

O trabalho infantil se tornou uma questão pública no país a partir, principalmente, do início da década de 1990, e o TID, apenas no final daquela década. Ações antes isoladas, como as do Ministério Público de São Paulo (1987) para enfrentar uso de mão de obra infantil no corte da cana-de-açúcar, foram sistematizadas por organizações como a OIT, o Unicef e outros atores sociais e ganharam atenção do Governo Federal. (VIVARTA, 2003) ${ }^{4}$

Em 1994, foi criado o Fórum Nacional de Prevenção e Erradicação do Trabalho Infantil (Fenapeti), uma entidade não governamental que busca articular e mobilizar os agentes institucionais envolvidos com o enfrentamento do trabalho infantil. A composição do Fórum é quadripartite. Participam representantes do Governo Federal, dos trabalhadores, dos empregadores e entidades da sociedade civil. Outras organizações, como a OIT e o Unicef, também compõem o Fenapeti. Uma das realizações mais relevantes do Fórum foi a criação, em 1999, da Rede Nacional de Combate ao Trabalho Infantil, composta por 52 organizações de todo o Brasil, além de 27 Fóruns Estaduais de Prevenção e Erradicação do Trabalho Infantil. ${ }^{5}$

Nesse período, foram criados programas federais de combate ao trabalho infantil, como o Programa de Erradicação do Trabalho Infantil (PETI), ${ }^{6}$ de 1996, e o Bolsa-escola, de 2001, que previam um valor mensal a ser pago às famílias para que as crianças e adolescentes frequentassem a escola ao invés de trabalhar. Os municípios também recebiam recursos para promover a jornada ampliada na escola, com aulas de reforço e atividades de arte-educação. Em 2005, o Governo Federal integrou o PETI ao Programa Bolsa-Família, criado em 2003, e que prevê transferência de renda a famílias pobres e extremamente pobres.

4 Um marco importante desse processo foi a chegada ao país do Programa Internacional para Eliminação do Trabalho Infantil (IPEC), implantado pela OIT, em 1992. Merecem destaque, ainda, as pesquisas (1992 e 1993) realizadas pelo Sindicato de Trabalhadores da Indústria de Calçados de Franca (SP) e da Central Única dos Trabalhadores (CUT) sobre o emprego de crianças e adolescentes na indústria calçadista.

5 Informações coletadas no site da Fenapeti. (FENPETI, [2011])

6 O PETI foi inspirado em uma iniciativa da OIT para o enfrentamento do trabalho infantil em carvoarias e na colheita de erva-mate, no Mato Grosso do Sul. (VIVARTA, 2003) 
No Pará, a discussão em torno do TID se iniciou em 2000, com a apresentação do estudo “Trabalho Doméstico de Meninas em Belém”, realizado por pesquisadoras da Universidade Federal do Pará (UFPA) para o Centro de Defesa da Criança e do Adolescente (Cedeca-Emaús). A Região Metropolitana de Belém, capital do Estado, foi escolhida pela OIT/IPEC para ser um dos lugares de realização de um programa piloto de combate ao TID, que também ocorreu em Belo Horizonte e Recife. A iniciativa foi executada, no Pará, pelo Cedeca-Emáus ${ }^{7}$ e foi chamada de Programa de Enfrentamento ao Trabalho Infantil Doméstico (Petid). ${ }^{8}$ A escolha do Cedeca-Emaús como principal parceiro se justifica pela estratégia dos organismos internacionais (OIT e Unicef) de dar ênfase a organizações locais com histórico de atuação na área de direitos humanos e direitos da criança. (BLACK, 2002)

Atuante desde a década de 1980, o Cedeca-Emaús foi o primeiro centro de defesa voltado para a infância e para a adolescência no país. Como marcos no trabalho do Cedeca estão o enfrentamento à violência cometida contra meninos e meninas trabalhadores do mercado do Ver-o-Peso, em Belém, o que levou à criação da entidade; a defesa dos direitos de meninos emasculados no município de Altamira (PA), um caso que ficou internacionalmente conhecido, ${ }^{9}$ e o combate a redes de exploração sexual e tráfico humano. Outras ações do CedecaEmaús também merecem destaque, como o monitoramento da execução de medidas socioeducativas no Pará, o combate à violência doméstica contra crianças e a proteção a meninos e meninas ameaçados de morte.

Por ser referência na área dos direitos da criança, o Cedeca-Emaús já vinha recebendo denúncias sobre situações de exploração envolvendo meninas domésticas, porém, sem apoio, o Centro não dispunha de meios para desenvolver ações de enfrentamento. (CENTRO DE DEFESA DA CRIANÇA E DO ADOLESCENTE; FUNDO DAS NAÇÕES UNIDAS PARA A INFÂNCIA, 2002) A partir de 1999, agentes do Cedeca-Emaús, a convite do escritório do Unicef em Belém, come-

7 O Petid tinha também o apoio, nos primeiros anos, do Unicef e da Save The Children, além de organizações locais. Nos últimos anos, a principal parceira internacional foi a Cordaid (Holanda).

8 O Petid inicialmente foi apoiado pelo Unicef e pela Save The Children.

9 No final dos anos 1980 e início dos anos 2000, vários meninos com idade entre 8 e 14 anos foram sequestrados e emasculados no município de Altamira, sudeste do Pará. A maioria foi assassinada. Segundo o Ministério Público, os acusados eram envolvidos com uma seita religiosa que alimentava esses rituais. Sete pessoas foram julgadas, a maioria foi condenada e uma absolvida. 
çaram a participar de reuniões e grupos interinstitucionais para discussão das propostas de enfrentamento ao TID. (CENTRO DE DEFESA DA CRIANÇA E DO ADOLESCENTE; FUNDO DAS NAÇÕES UNIDAS PARA A INFÂNCIA, 2002) Tratava-se, portanto, de uma instituição com trabalho consolidado na área da infância e da adolescência e com a inserção local necessária para protagonizar o enfrentamento ao TID. No entanto, era preciso ter apoio amplo de diferentes organizações sociais e governamentais para dar retaguarda a essa ação. Desse modo, foi estruturado um Comitê Gestor do Petid, protagonizado pelo CedecaEmaús. ${ }^{10}$ A gestão do Petid foi pensada de modo a estimular que as ações do programa se tornassem políticas no município de Belém e no Estado.

De acordo com informações coletadas durante nossa pesquisa de mestrado (CAL, 2007), houve problemas para efetivar esse modelo de gestão compartilhada do Petid, principalmente em relação à participação dos órgãos governamentais. Apesar de a proposta corroborar a promoção da corresponsabilidade pelo enfrentamento do TID, isso não foi suficiente para incentivar de modo consistente e contínuo políticas de combate a essa prática. Entre os fatores que podem ter contribuído para isso, está a participação descontínua de representantes dos executivos municipal e estadual nas reuniões do Petid. Por vezes, a cada reunião do Petid, uma pessoa diferente participava representando o mesmo órgão. ${ }^{11}$ Mesmo assim, a participação, em geral, estava restrita a níveis mais operativos (técnicos) e não a esferas decisórias dentro dessas instituições.

Havia, portanto, em relação ao TID, um pano de fundo normativo que embasava o engajamento de organizações sociais e governamentais no enfrentamento desse problema. Todavia, um grande desafio ao qual o Petid se deparou foi conseguir estimular políticas públicas adequadas e suficientes para erradicação do TID.

10 Outras instituições parceiras eram: Superintendência Regional do Trabalho (antiga DRT), Ministério Público do Trabalho e Procuradoria do Trabalho, Sindicato dos Trabalhadores Domésticos, Arrumadores e Camareiros de Belém e Ananindeua, Movimento República de Emaús, Universidade Federal do Pará, Fundação Jorge Duprat e Figueiredo (FUNDACENTRO), Fundação Papa João XXIII, Fundação da Criança e do Adolescente do Pará (Funcap, hoje chamada Fasepa), UNICEF, Secretaria Executiva de Trabalho e Promoção Social do Estado (hoje chamada Secretaria de Estado de Assistência Social, Trabalho, Emprego e Renda - Seaster).

11 Informações obtidas por meio de entrevista concedida à pesquisadora, em 25 de janeiro de 2007, pelo assessor de comunicação do Petid até 2005. 


\section{PRINCIPAIS AÇÕES DO PETID E DESAFIOS ENFRENTADOS}

Como apresentamos anteriormente, o Petid foi lançado em $2000 \mathrm{com}$ apoio do Unicef e da Save The Children. A primeira ação foi a realização da já citada pesquisa “Trabalho Doméstico de Meninas em Belém”. Os principais problemas apontados pelo estudo foram o alto índice de defasagem escolar, ou seja, as meninas envolvidas com o TID não estavam cursando séries compatíveis com suas idades; as jornadas de trabalho excessivas; as perdas de vínculos familiares; o abuso sexual e a baixa autoestima das meninas que eram chamadas pejorativamente de "caboquinhas"12 por terem vindo de municípios do interior amazônico e por apresentarem traços indígenas. (CENTRO DE DEFESA DA CRIANÇA E DO ADOLESCENTE, 2002)

A partir desse retrato inicial, o Cedeca-Emaús e os parceiros desenvolveram estratégias para estimular a autoestima das meninas envolvidas no TID. O foco nesse primeiro momento foi a valorização da cultura e da identidade amazônicas. Foram realizadas oficinas educativas com as adolescentes do projeto, além da capacitação de professores e agentes sociais para utilizarem um kit pedagógico, que abordava de modo lúdico e regionalizado o TID.

O Petid organizou também reuniões com diferentes públicos (empresários, representantes da Igreja, associações comunitárias) para sensibilizar em torno da temática em questão e contribuir para "desnaturalizar" esse tipo de trabalho infantil. (CENTRO DE DEFESA DA CRIANÇA E DO ADOLESCENTE, 2002) Também foram realizadas oficinas de geração de renda para adolescentes e pais, além de cursos profissionalizantes. O Cedeca-Emaús e parceiros também promoveram reuniões com grupos de pais. Esses encontros tinham o objetivo de esclarecer sobre o trabalho TID e de fortalecer a família como retaguarda para que crianças e adolescentes fossem retirados da situação de trabalho infantil. Algumas famílias também foram encaminhadas a programas governamentais de assistência social e de geração de renda.

\footnotetext{
12 O termo não está dicionarizado, mas é correntemente utilizado no linguajar paraense. "Caboquinha do interior" é um modo, em geral, pejorativo de se referir a meninas e mulheres, principalmente, de origens ribeirinhas, ou seja, oriundas de municípios banhados por rios e afluentes. Essa expressão quer dizer que a pessoa não sabe se comportar em determinados ambientes ou não sabe se vestir adequadamente. Em última instância, é uma depreciação do valor dessas mulheres, sobretudo em contraposição aos modos de ser na cidade.
} 
Com a finalidade de, mais diretamente, envolver crianças e adolescentes no projeto, foram criados grupos de meninos e meninas que se reuniam periodicamente com técnicos do Petid para participar de momentos de formação e contribuir com o enfrentamento ao TID. Foram cinco grupos em Belém, que envolviam de 15 até 50 crianças e adolescentes, e um grupo no município de Soure, na Ilha do Marajó, no Pará, onde o Programa iniciou uma ação piloto com o objetivo de desestimular a saída de meninas para o serviço doméstico em Belém. (CENTRO DE DEFESA DA CRIANÇA E DO ADOLESCENTE, 2004; CAL, 2013)

Entre os principais desafios do Petid destacados pelas publicações do Cedeca-Emaús, estava a dificuldade de algumas meninas e famílias em aceitar a intervenção. As que aceitavam apresentaram dificuldades para acompanhar adequadamente os cursos profissionalizantes, apesar de estarem em idade compatível com essa formação. Outro problema que os parceiros do Petid encontraram foi não conseguir garantir o atendimento adequado e suficiente a essas adolescentes e às famílias na rede de assistência do município de Belém e do estado do Pará. (CENTRO DE DEFESA DA CRIANÇA E DO ADOLESCENTE, 2002) Há, ainda, o relato da dificuldade para convencer os próprios atores sociais envolvidos nessas instituições de que o TID era um problema a ser enfrentado. Identificaram-se, entre os parceiros, patrões e patroas de meninas trabalhadoras domésticas.

De acordo com o relatório do Cedeca-Emaús,

Inclusive entre os parceiros que defendem a perspectiva de direitos da infância e da adolescência, se encontram pessoas que empregam meninas e defendem o trabalho infantil doméstico como estratégia de proteção às meninas para que não vivam em uma situação de maior miséria com suas famílias. (CENTRO DE DEFESA DA CRIANÇA E DO ADOLESCENTE, 2002, p. 41)

Assim, a naturalização desse tipo de atividade e a falta de reconhecimento como um trabalho se apresentavam, ainda, como desafios a serem considerados na construção do posicionamento interno e público do Petid. Antes de iniciar uma abordagem pública acerca da temática, o Cedeca-Emaús estimulou, por meio de encontros e reuniões, a sensibilização dos parceiros acerca do TID. 
Outra dificuldade enfrentada pelo Petid foi conseguir garantir o engajamento dos próprios adolescentes na luta contra o TID. Por meio do acompanhamento que realizamos do Petid, desde 2000 até 2009, observamos que o Programa enfrentou dificuldades metodológicas e sociais para colocar em prática essa proposta. Tais dificuldades estavam relacionadas à construção de metodologias e técnicas adequadas para garantir essa participação e estimular espaços concretos para que eles fossem considerados protagonistas do processo por atores e instituições membros do Conselho Gestor, mais resistentes a reconhecer a atuação política de crianças e adolescentes. ${ }^{13}$ Um grupo pequeno de adolescentes atuou como bolsistas do Cedeca e como estagiários do Petid e teve maior participação nas ações e atividades realizadas.

Como temos discutido neste capítulo, o enfrentamento ao TID no Pará começou por meio da ação de grupos (internacionais e locais) de advocacy em torno dos direitos da criança e do adolescente. Segundo Rousiley Maia, (2012), processos de discussão social ampliada acerca de injustiças que afetam determinados grupos não precisam ser iniciados necessariamente pelos próprios afetados, pois eles podem não estar em condições de exercer esse papel, já que podem se encontrar em situação de exploração e sujeitos a outras vulnerabilidades. "Neste caso, os críticos sociais, defensores de certas causas, empreendedores morais, ou membros de movimentos sociais que têm afinidade ou se identificam com a situação vivida por tais sujeitos podem iniciar o processo de deliberação e de autorreflexão”. (MAIA, R., 2012, p. 41-42, tradução nossa) Para a autora, os agentes de advocacy criam e propiciam recursos e oportunidades para tematização pública do problema em tela. Nesse sentido, "eles podem ser bem sucedidos em sustentar o debate na esfera pública, incluindo o ambiente dos media" (MAIA, R., 2012, p. 42, tradução nossa, grifo nosso), o que pode contribuir para o questionamento de práticas arraigadas socialmente, como o TID. Entretanto, permanece a tensão acerca da "autoexpressão dos dominados” (MIGUEL, 2011) em processos políticos de representação mais ampla de meninos e meninas na

13 A situação foi distinta em Soure, onde o grupo de adolescentes protagonistas, sob orientação de educadores do Cedeca-Emaús e apoio da prefeitura, desenvolveram atividades protagônicas no município. No entanto, com mudanças na administração da prefeitura, alteração de faixa etária dos adolescentes envolvidos e reestruturações internas do Petid, esse grupo acabou se esvaziando. Importante ressaltar que se tratavam, sobretudo, de adolescentes que poderiam vir a ser trabalhadores infantis domésticos por viverem em contextos que estimularam a saída de outros para o serviço doméstico na capital. (CAL, 2013) 
qual figuras de autoridade e especialistas tendem a definir o que seria melhor para elas. (MIGUEL, 2011; EARLS, 2011) Assim, argumentamos que, no contexto de ações de advocacy empreendidas por organizações sociais contra o TID, é necessário investigar o que os sujeitos afetados têm a dizer acerca do assunto.

Fonseca e Cardarello (1999) analisam como a noção de direitos humanos é traduzida na prática a partir de campanhas de reivindicação de direitos empreendidas por ativistas e organizações em nome de sujeitos subalternizados. A questão levantada pelas autoras é pertinente para a discussão que empreendemos neste artigo sobre os limites do advocacy: "que vantagens tiram esses grupos ‘subalternos' dessas embalagens mediáticas?”. (FONSECA; CARDARELLO, 1999, p. 85) Elas ressaltam que, apesar das campanhas dos ativistas serem fundamentais para inserir temas sociais na agenda política, essas "frentes discursivas" podem acabar reificando o grupo que deseja defender, pois "correm o risco de montar programas que não apenas deixam de alcançar os seus objetivos, mas, pior que isto, produzem novas formas de exclusão". (FONSECA; CARDARELLO, 1999, p. 85) É verdade que grupos subalternos, sobretudo os pouco organizados politicamente, como os das trabalhadoras infantis domésticas, possuem possibilidades escassas de participação efetiva nas discussões públicas que lhes dizem respeito. Nesse sentido, as ações de advocacy contribuem para manifestar publicamente injustiças vividas por esses sujeitos. Entretanto, o que Fonseca e Cardarello (1999) alertam é que a defesa abstrata de certos direitos, principalmente a partir de uma perspectiva externa aos concernidos, pode obscurecer práticas e percepções desses sujeitos. Ou, nas palavras das autoras, deve-se evitar "misturar os nomes que nós inventamos com a realidade que os outros vivenciam”. (FONSECA; CARDARELLO, 1999, p. 118)

Portanto, torna-se essencial, e esse é o interesse de nossa pesquisa, questionar: como meninas e mulheres diretamente afetadas pelo TID se posicionam em relação a essa temática? Trata-se meramente da reprodução de discursos opressores? E, principalmente, como certo jogo entre diferentes relações de poder atua na configuração política do TID a partir das próprias envolvidas num contexto social em que há grupos de advocacy questionando essa prática?

Como parte dessa conjuntura de enfrentamento ao TID, é preciso considerar as estratégias de Comunicação do Petid e o modo pelo qual o assunto foi tratado publicamente por meio de campanhas de publicidade e pelos media. 


\section{Comunicação do Petid e Media Advocacy}

Em relação às ações mais amplas na área de Comunicação, o Petid lançou, entre 2001 e 2007, três campanhas contra o TID $^{14}$ e procurou se aproximar dos media locais com a finalidade de garantir cobertura jornalística sobre o assunto. Consta em relatórios do Petid a realização de oficinas com jornalistas sobre o tema e que o combate ao TID "ganhou grande apoio dos meios de comunicação locais”. (CENTRO DE DEFESA DA CRIANÇA E DO ADOLESCENTE, 2002, p. 17) Além disso, as Organizações Rômulo Maiorana (ORM), responsáveis pelo Grupo Liberal (TV, jornal impresso e rádios, afiliada, no Pará, da Rede Globo), atuaram convocando outros empresários a se unir pela temática por meio da Câmara Setorial de Responsabilidade Social, da Associação Comercial do Pará ${ }^{15}$.

Como discutimos em nossa dissertação de mestrado (CAL, 2007), entre os anos de 2000 a 2004, as estratégias do Petid para a construção do discurso do TID como um problema foram bastante cuidadosas para que não provocassem um confronto agressivo com a cultura local. (CENTRO DE DEFESA DA CRIANÇA E DO ADOLESCENTE, 2002) Nesse sentido, era fundamental "evitar o tom agressivo na abordagem da campanha de sensibilização contra o trabalho doméstico infantil e no contato com parceiros, instituições e famílias, para evitar uma reação inversa que poderia promover um efeito contrário”. (CENTRO DE DEFESA DA CRIANÇA E DO ADOLESCENTE, 2002, p. 15) Por efeito contrário, os agentes do Petid previam a defesa desse tipo de prática e também dos patrões pelas próprias meninas trabalhadoras domésticas, que compartilhavam discursos legitimadores do trabalho infantil. Procurava-se evitar também "uma superexposição das vítimas ou mesmo o tratamento assistencialista-ingênuo dado às crianças e adolescentes como se elas fossem 'coitadinhas', demandando a piedade e as atitudes paternalistas da sociedade”. (CENTRO DE DEFESA DA CRIANÇA E DO ADOLESCENTE, 2002, p. 40)

14 Nacionalmente, de modo paralelo, organizações como OIT, Unicef, Fundação Abrinq, Ministério Público do Trabalho e Andi criaram campanhas publicitárias com objetivo de chamar atenção social para o TID. A Andi foi a principal articuladora nacional entre fontes relacionadas ao trabalho doméstico infantil e os media, com a divulgação de materiais específicos para subsidiar o trabalho jornalístico, pesquisas e encontros de capacitação sobre o tema. Além disso, regionalmente, os projetos de combate ao TID criaram suas próprias campanhas e ações de comunicação, como foi o caso do Petid, de Belém.

15 Essa parceria está evidente no convite impresso feito para convocar empresários para um café da manhã sobre o TID; também consta de modo bastante claro nos relatórios do Programa e em matérias jornalísticas publicadas em $O$ Liberal. 
Em relação à cobertura jornalística local acerca do TID nos primeiros anos do Petid, observamos, em outro momento (CAL, 2007; CAL; MAIA, R., 2012), que as principais fontes ouvidas representavam o Cedeca-Emaús ou seus parceiros. Além disso, os enquadramentos que predominaram nos jornais estudados entre 2000 e 2004 eram compatíveis com as perspectivas defendidas pelos agentes do Petid. Os dois principais se referiam: (1) à invisibilidade do TID e (2) às injustiças relacionadas a essa prática. O primeiro dizia respeito ao modo naturalizado pelo qual o trabalho infantil era (é) considerado pela sociedade, aos desafios da tematização pública por se realizar em ambiente íntimo dos lares e a aspectos de gênero que fazem com que essa prática não seja questionada. O segundo enquadramento diz respeito às injustiças do TID e engloba discursos que consideram este tipo de trabalho uma forma de exploração de crianças e adolescentes, uma violação de direitos e uma "falsa" caridade. De modo geral, os media estudados ressaltaram os aspectos negativos relacionados ao TID, do ponto de vista dos direitos da infância e da adolescência (CAL, 2007), e concederam espaços de fala para os agentes e parceiros do Petid. No período investigado anteriormente, não tiveram visibilidade, discursos legitimadores do TID. Portanto, não houve controvérsia na tematização pública desse assunto. Por essas razões, e por constarem formalmente como parceiros do Programa, consideramos que os media atuaram também como agentes de advocacy (MAIA, R.; CAL, 2012), ao promoverem o enfrentamento ao TID por meio da cobertura jornalística e por recorrerem aos discursos do Petid e de parceiros para se posicionar acerca do tema.

A primeira campanha de publicidade desenvolvida pelo Petid ocorreu em duas fases: (1) a inicial foi realizada entre 2001 e 2002 e teve como objetivo a apresentação do problema do TID. Com o título "A construção do futuro começa em casa", o cartaz da campanha remete ao discurso de que "as crianças são o futuro" (Figura 1) e, portanto, o cuidado com elas deve começar no espaço doméstico. Construir um futuro melhor para crianças e adolescentes começaria, assim, pela garantia dos direitos deles em casa; (2) a segunda, lançada em 2004, teve como título a frase "Com o trabalho infantil doméstico, não dá pra ser criança”, para dizer que o este tipo de trabalho exige responsabilidades que não são apropriadas ao tempo da infância. Haveria, portanto, uma incompatibilidade entre "trabalho" e "ser criança". Naquele momento, a preocupação do Petid era estimular as denúncias contra essa prática. 


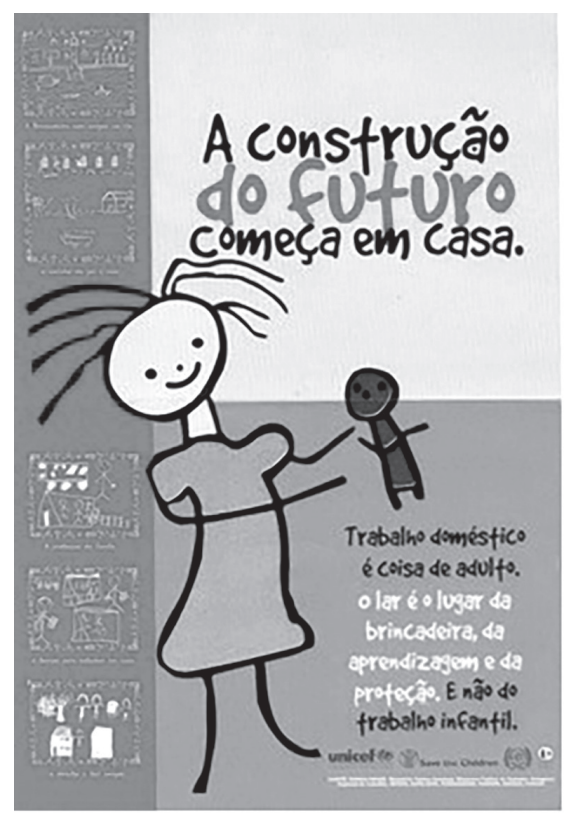

Figura 1 - Cartaz da primeira fase do Petid Fonte: Petid.

O foco da primeira fase da campanha era estimular a percepção social de que o trabalho doméstico violava os direitos de crianças e adolescentes e restringia as oportunidades de escolha profissional. É nesse sentido que "A construção do futuro começa em casa”. No folder dessa fase (Figuras 2 e 3), foram expressos desejos profissionais de quatro adolescentes ouvidas na pesquisa "Trabalho Doméstico de Meninas em Belém”, acompanhados de uma breve contextualização sobre a situação de cada uma delas, como, por exemplo: “'Quero continuar os estudos e ser médica', Sálvia. Envolvida com o trabalho doméstico desde os 12 anos" e "Quero ser advogada'. Ébano ${ }^{16}$. Seu padrasto bebia e ficava violento com ela e sua mãe"'. O texto do folder desenvolve a ideia de que o TID pode resultar em violência contra crianças e adolescentes envolvidos e que ele viola direitos básicos, como à convivência familiar e comunitária, ao aprendizado na escola e à escolha profissional.

16 Para que as adolescentes não fossem identificadas, foram usados nomes de flores como pseudônimos. 

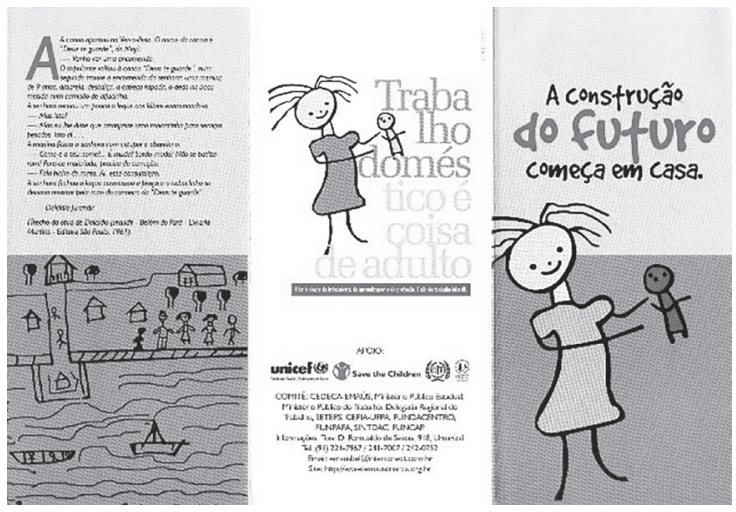

Figura 2 - Lado externo do folder geral Fonte: Petid.

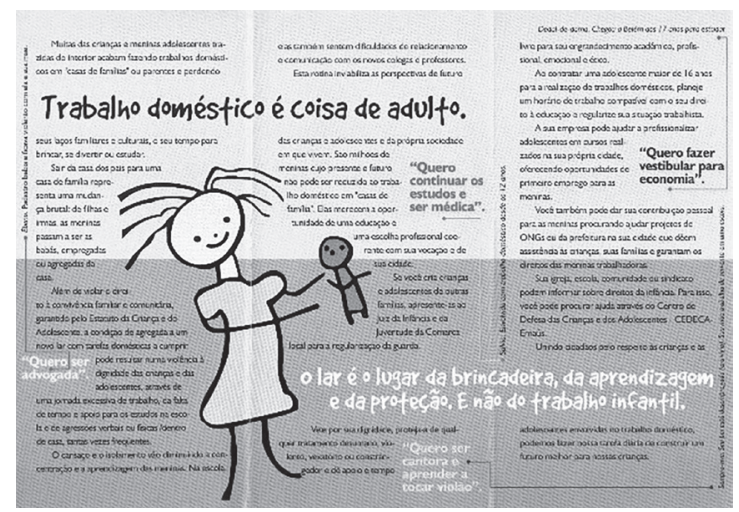

Figura 3 - Lado interno do folder geral Fonte: Petid.

O TID, portanto, subtrai o período da infância e a condição de realização de sonhos futuros, pois afasta as crianças e adolescentes trabalhadoras de outro tipo de inserção no mercado de trabalho, em condições consideradas mais vantajosas, como nas profissões de médica ou advogada. Em contraposição a argumentos legitimadores do serviço doméstico realizado por crianças e adolescentes, como o de que esse tipo de trabalho infantil seria uma oportunidade de ter acesso à educação de qualidade, o discurso do Petid procurou apresentar aspectos negativos do TID, tais como os prejuízos educacionais por conta de lon- 
gas jornadas e do cansaço, a violência sob a forma de humilhações e agressões e a perda do convívio familiar e comunitário. Ainda assim, o texto do folder é bastante cuidadoso para não afrontar a "cultura local" e solicita a pessoas que criem meninos e meninas de outras famílias que os apresentem ao juiz para regularização da guarda. Solicita ainda que eles sejam tratados com dignidade, mas não afirma a proibição do TID. De modo complementar, o discurso do Petid buscou reforçar a imagem positiva do trabalho doméstico realizado por maiores de idade: “Trabalho doméstico é coisa de adulto. O lar é o lugar da brincadeira, da aprendizagem e da proteção. E não do trabalho infantil”.

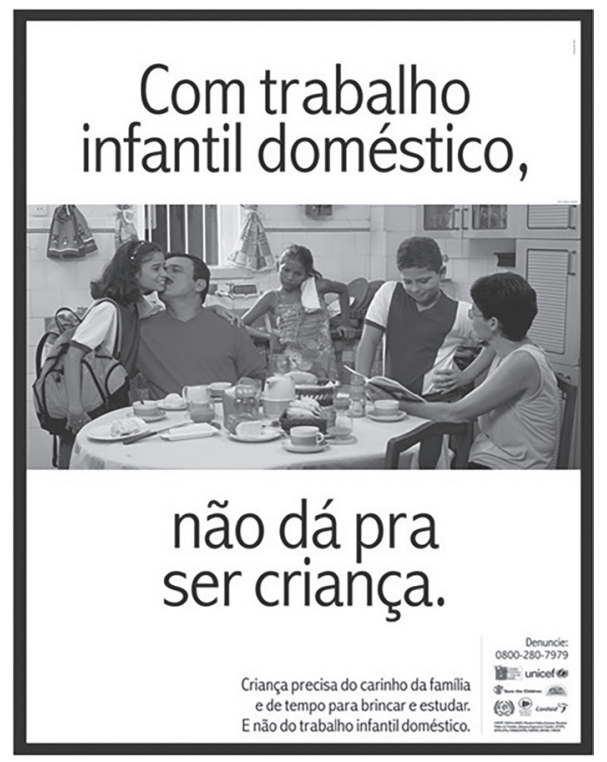

Figura 4 - Cartaz da segunda fase do Petid Fonte: Petid.

Lançada em 2004, a segunda fase da campanha ocorre quando o TID já havia sido tematizado publicamente, não apenas pelo Petid, mas também na cobertura da imprensa. A ideia principal trabalhada nas peças publicitárias era a de que o trabalho doméstico é incompatível com a infância, conforme podemos observar no cartaz (Figura 4). Há um afastamento em relação às referências infantis da primeira fase, como desenhos, cores alegres e fortes (as principais cores utilizadas foram o amarelo, o laranja e o vermelho). Nessa fase da campanha, a 
referência à invisibilidade do TID é destacada por meio da foto que participa de todas as peças. No centro da imagem, que é colorida, há uma menina em preto e branco recostada sobre a pia da cozinha, com um pano de prato sobre os ombros e com uma expressão triste e distante, contrapondo-se à felicidade dos filhos do casal que recebem carinho e atenção dos pais. O principal objetivo é estimular uma reflexão crítica acerca dos lugares e papéis que essas meninas ocupam nos lares e na sociedade. Nesse estágio da campanha, o Petid incentivou claramente denúncias de situações de TID.

No folder em questão, a contraposição entre a imagem da menina doméstica e das crianças da família empregadora fica ainda mais destacada (Figuras 5 e 6). No texto, há informações sobre os principais motivos para a ocorrência do TID. São citados a falta de oportunidades de emprego e renda para as famílias em municípios do interior; a falta de informação de muitas famílias de origem sobre a real situação das filhas na capital e, por fim, a naturalidade com a qual a sociedade aceita o TID. Os principais problemas levantados no primeiro momento da campanha são reforçados, como maus-tratos, perda da infância e do direito ao bom aproveitamento dos estudos. Nessa peça, há informações sobre como o Programa está sendo desenvolvido e a indicação de que meninos e meninas têm levado informações sobre direitos da criança a escolas de Belém, de Soure e de Salvaterra. Por fim, há uma convocação para que os cidadãos se envolvam no enfrentamento ao TID e denunciem quem emprega crianças.

Nessas duas fases da campanha de publicidade, o discurso do Petid se baseou no enfrentamento ao TID a partir de uma perspectiva de direitos, de tal modo que esse tipo de prática fosse enquadrado como uma injustiça. Isso porque, às meninas trabalhadoras domésticas, são negados direitos básicos, como o de conviver com a família e com amigos, o de ter sucesso na escola e o de poder escolher uma carreira profissional. As peças apresentadas até então reforçam o cuidado do Petid em não realizar um confronto agressivo com os discursos que alimentam o TID. Ao invés de apresentar os empregadores de crianças e adolescentes como "exploradores", o Petid procurou ressaltar (a) os problemas relacionados ao TID (falta de tempo para brincar e estudar, agressões físicas e verbais, perda da convivência familiar e comunitária) e (b) a responsabilidade de toda a sociedade pela garantia dos direitos de meninos e meninas. 

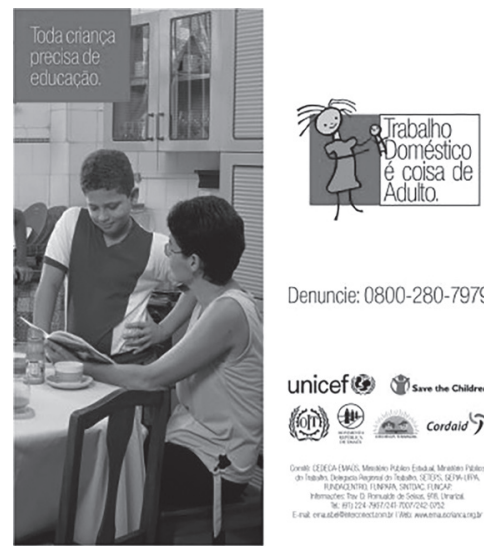

Denuncie: 0800-280-7979

unicef (3)

(6in) (110) cordoid'

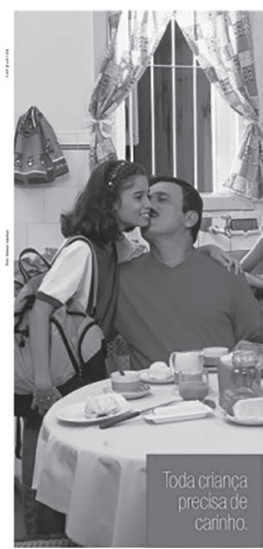

Figura 5 - Parte externa ao folder da segunda fase Fonte: Petid.

Com trabalho infantil doméstico, não dá pra ser criança.

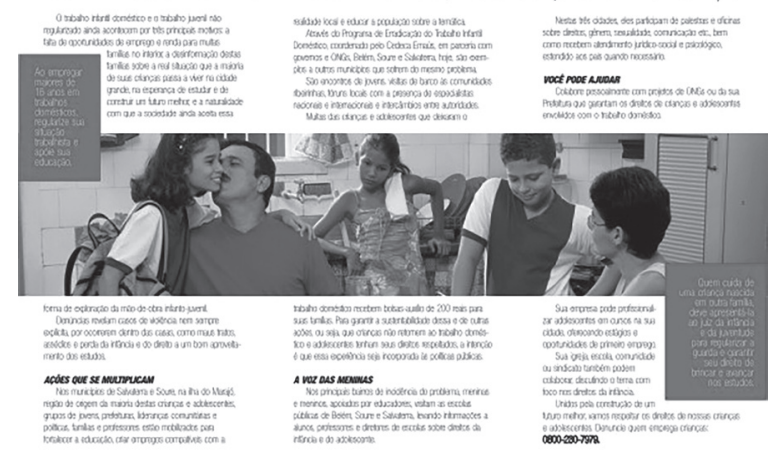

Figura 6 - Parte interna ao folder da segunda fase Fonte: Petid. 


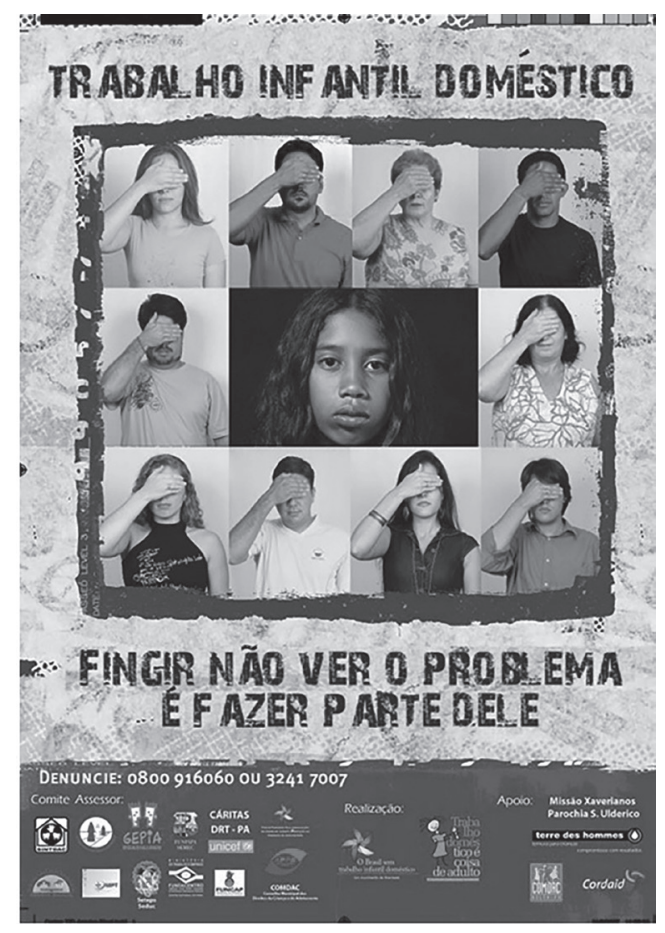

Figura 7 - Cartaz da campanha do Petid de 2007 Fonte: Petid.

Em 2007, o Petid lançou uma nova campanha que questionava de modo mais agressivo a "invisibilidade" do TID. O slogan era "Não ver o problema é fazer parte dele”. No cartaz (Figura 7), figura a imagem de uma menina negra no centro e, ao redor, fotografias de pessoas com diferentes características físicas e estilos de se vestir tapando os olhos. A peça chama à responsabilidade de modo distinto daquele que vinha sendo feito até então. Se, num primeiro momento, o discurso do Petid era o de que cabia à sociedade em geral respeitar os direitos de meninos e meninas, a partir de 2007 , a sociedade passou a ser considerada culpada pelo problema, na medida em que o aceitava ou fingia não vê-lo.

O texto do folder (Figura 8) é ainda mais enfático. Há respostas diretas e duras a vários discursos que legitimam o TID, como, por exemplo, de que é uma forma de ajudar crianças pobres. Sobre o que é TID, o texto do folder afirma que se trata de uma das principais formas de exploração da criança e do adolescente. 
"O Trabalho Infantil Doméstico é cruel porque, mesmo quando estudam, as meninas têm baixo rendimento escolar, e a maioria para de estudar". (PROGRAMA DE ENFRENTAMENTO DO TRABALHO INFANTIL DOMÉSTICO, 2007, 1 folder) Embora o prejuízo relacionado à educação tenha sido trabalhado nos dois outros momentos da campanha publicitária do Petid, é a primeira vez que está relacionado à crueldade.

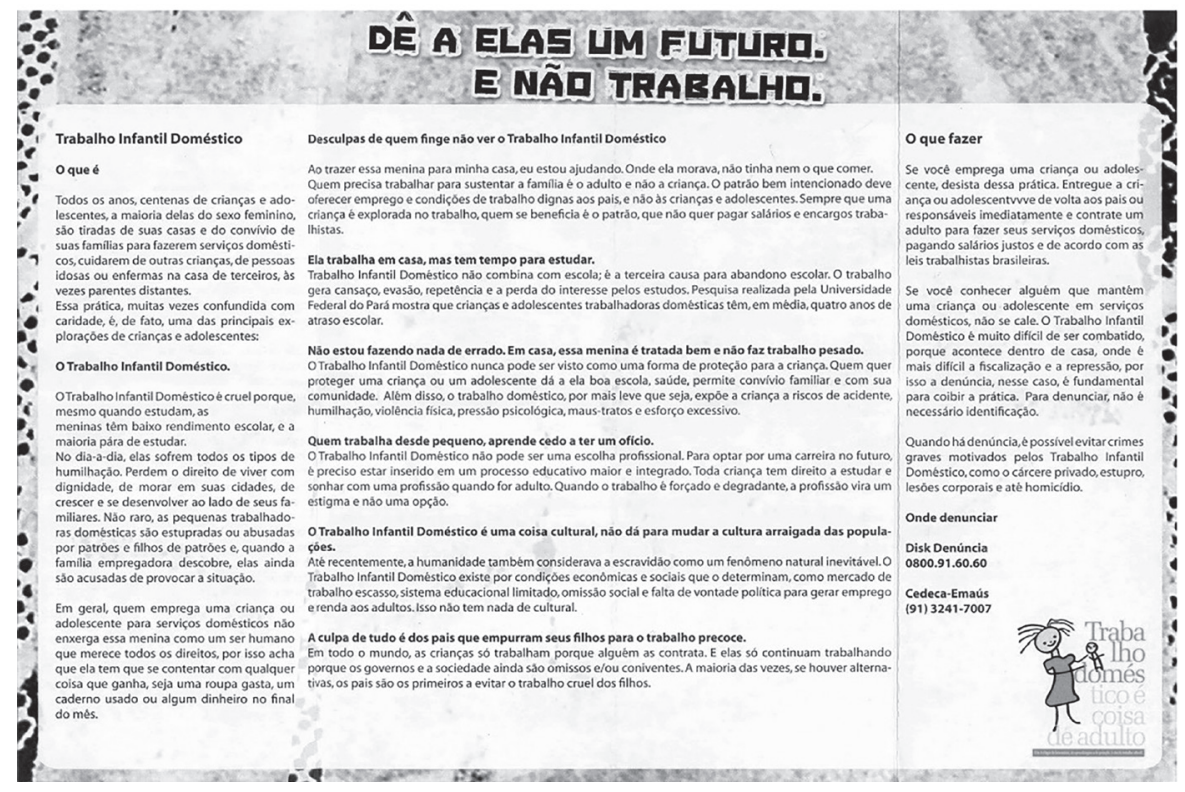

Figura 8 - Parte interna do folder da campanha 2007

Fonte: Petid.

Em relação aos empregadores, a forma de se dirigir a esse público é bem distinta da utilizada nas peças de 2001 e 2004:

Em geral, quem emprega uma criança ou adolescente para serviços domésticos não enxerga essa menina como um ser humano que merece todos os direitos, por isso acha que ela tem que se contentar com qualquer coisa ganha, seja uma roupa gasta, um caderno usado ou algum dinheiro no final do mês. (PROGRAMA DE ENFRENTAMENTO DO TRABALHO INFANTIL DOMÉSTICO, 2007, 1 folder) 
Percebe-se que o Petid mudou, então, de estratégia e abandonou a postura diplomática dos seus primeiros materiais de publicidade (CAL, 2007) ao, inclusive, culpar diretamente os empregadores pelo TID:

Se você emprega uma criança ou adolescente, desista dessa prática.

Entregue a criança ou o adolescente de volta aos pais ou responsáveis imediatamente e contrate um adulto para fazer seus serviços domésticos, pagando salários justos e de acordo com as leis trabalhistas brasileiras. (PROGRAMA DE ENFRENTAMENTO DO TRABALHO INFANTIL DOMÉSTICO, 2007, 1 folder)

O modo de orientar quem possui a guarda não regularizada de meninos e meninas e os coloca para realizar trabalho doméstico também ficou direto e enfático no sentido de dizer o que está certo ou errado, de acordo com o posicionamento defendido pelo Petid. O trecho reforça, ainda, o posicionamento da criança e do adolescente como vítima que está sujeita à sorte imposta pela família empregadora.

De modo geral, a partir das campanhas e do relacionamento com os meios de comunicação, os agentes do Petid procuraram dar visibilidade ao TID como uma questão coletiva. Consideramos que o discurso da "invisibilidade", tão trabalhado pelo Programa, contribuiu para lançar luz sobre o TID como um problema que merece preocupação coletiva, mas, parece-nos, atribuiu aos sujeitos envolvidos uma condição de subordinação e subalternidade, que os colocou na posição de vítimas, e não de sujeitos políticos.

A partir desse contexto, interessa-nos os conceitos de "político" e de "relações de poder”, com os quais dialogaremos na análise, o que faremos no capítulo seguinte. 